\title{
Publisher Correction: Deacetylation of serine hydroxymethyl-transferase 2 by SIRT3 promotes colorectal carcinogenesis
}

Zhen Wei ${ }^{1}$, Jinglue Song ${ }^{2,3}$, Guanghui Wang ${ }^{2,3}$, Ximao Cui ${ }^{2,3}$, Jun Zheng ${ }^{1}$, Yunlan Tang ${ }^{1}$, Xinyuan Chen ${ }^{1}$, Jixi Li', Long Cui ${ }^{2,3}$, Chen-Ying Liu ${ }^{2,3} \&$ Wei Yut,2

Correction to: Nature Communications https://doi.org/10.1038/s41467-018-06812-y. published online 26 Oct 2018.

The original version of this Article contained an error in the Data Availability Statement. The accession code indicated '53V' and should have read ' $5 \mathrm{X} 3 \mathrm{~V}$ '. This has been corrected in both PDF and HTML versions of the Article.

Published online: 12 February 2019

\footnotetext{
(c) (i) Open Access This article is licensed under a Creative Commons Attribution 4.0 International License, which permits use, sharing, adaptation, distribution and reproduction in any medium or format, as long as you give appropriate credit to the original author(s) and the source, provide a link to the Creative Commons license, and indicate if changes were made. The images or other third party material in this article are included in the article's Creative Commons license, unless indicated otherwise in a credit line to the material. If material is not included in the article's Creative Commons license and your intended use is not permitted by statutory regulation or exceeds the permitted use, you will need to obtain permission directly from the copyright holder. To view a copy of this license, visit http://creativecommons.org/licenses/by/4.0/.
}

(c) The Author(s) 2019

\footnotetext{
${ }^{1}$ State Key Laboratory of Genetic Engineering and Collaborative Innovation Center for Genetics and Development, School of Life Sciences and Zhongshan Hospital, Fudan University, Shanghai 200438, China. ${ }^{2}$ Department of Colorectal and Anal Surgery, Xinhua Hospital, Shanghai Jiao Tong University School of Medicine, Shanghai 200092, China. ${ }^{3}$ Shanghai Colorectal Cancer Research Center, Shanghai 200092, China. Correspondence and requests for materials should be addressed to L.C. (email: cuilong@xinhuamed.com.cn) or to C.-Y.L. (email: liuchenying@xinhuamed.com.cn) or to W.Y. (email: yuw@fudan.edu.cn)
} 